\title{
Perbandingan Daya Dukung Tiang Pancang Berdasarkan Data CPT dan Data SPT Pada Pondasi Gedung Parkir RSUD Soedono
}

\section{Comparison of Pile Carrying Capacity Based on CPT Data and SPT Data on the Foundation of Soedono Hospital Parking Building}

\author{
Arik Triarso ${ }^{1}$ \\ ${ }^{1}$ Jurusan Teknik Sipil, Fakultas Teknik, Universitas Negeri Surabaya, Jln. Ketintang Surabaya. Email : \\ ariktriarso@unesa.ac.id.
}

\begin{abstract}
Abstrak
Proyek pembangunan Gedung Parkir RSUD Dr. Soedono Madiun melakukan pengujian CPT dan SPT sekaligus untuk mendapatkan daya dukung pondasi. Oleh karena itu dua metode perhitungan daya dukung berdasarkan data CPT dan data SPT perlu dilakukan untuk dapat mengetahui perbandingan dari keduanya. Proses pengumpulan data di dalam penelitian ini dimulai dengan pengamatan data dari pengujian tanahyang terdiri dari SPT dan CPT. Pengolahan data dilakukan dengan mencari titik CPT dan SPT yang berdekatan lokasi pengujiannya, kemudian dari data CPT dicari nilai konus, JHP (Jumlah hambatan pelekat), dan rasio gesek. Sedangkan dari data SPT dicari nilai N (jumlah pukulan). Kemudian dari data tersebut dilakukan analisa daya dukung pondasinya. Hasil estimasi perkiraan jenis tanah dari data CPT secara garis besar sama dengan diskripsi visual jenis tanah dari data SPT. Hasil SPT dan CPT memberikan informasi kriteria yang sama. Hasil perhitungan daya berdasarkan data SPT dan CPT memberikan hasil yang relatif sesuai. Hasil perhitungan kapasitas daya dukung kelompok tiang pancang berdasarkan data SPT dan CPT memberikan jumlah tiang pancang yang sesuai.
\end{abstract}

Kata Kunci: SPT; CPT; daya dukung pondasi

\begin{abstract}
The construction project of Dr. Soedono Madiun tested the CPT and SPT at the same time to obtain the bearing capacity of the foundation. Therefore, two methods of calculating carrying capacity based on CPT data and SPT data need to be done to be able to find out the comparison of the two. The data collection process in this study began with the observation of data from soil testing consisting of SPT and CPT. Data processing is carried out by looking for CPT and SPT points that are close to the test location, then from the CPT data the conus value, JHP (amount of sticking resistance), and friction ratio are looked for. Meanwhile, the SPT data looked for the value of $N$ (number of strokes). Then from the data, analysis of the bearing capacity of the foundation is carried out. The estimation results of soil type estimates from the CPT data are broadly the same as the visual descriptions of soil types from the SPT data. The SPT and CPT results provide the same criteria information. The results of power calculations based on SPT and CPT data provide relatively appropriate results. The results of the calculation of the carrying capacity of pile groups based on SPT and CPT data provide the appropriate number of piles.
\end{abstract}

Keywords: SPT; CPT; bearing capacity

\section{PENDAHULUAN}

Daya dukung pondasi dalam suatu bangunan dapat dihitung dengan berdasarkan beberapa macam data dari hasil pengujian tanah. Ada dua jenis pengujian tanah yaitu uji lapangan dan uji laboratorium. (Shiley, 1994). 
Uji lapangan yang sering diunakan di lapangan dapat berupa SPT (Standard Penetration Test) dan CPT (Cone Penetration Test). Pengujian lapangan ini dinilai cukup praktis dibandingkan uji laboratorium karena untuk 1 titik hanya dilakukan dengan 1 kali salah satu pengujian SPT atau CPT saja. Sedangkan untuk 1 titik uji laboratorium cukup banyak yang perlu dilakukan yaitu terdiri dari serangakaian pengujian sampel tanah yang diambil dengan sistem boring kemudian dilakukan pengujian sesuai standar ASTM meliputi uji volgrav, analisa ayakan, dan uji geser (Das, 1986). Uji laboratorium tersebut dilakukan pada sampel tanah dengan interval kedalaman setiap $2 m-3 m$.

SPT adalah suatu metode uji yang dilaksanakan bersamaan dengan pengeboran untuk mengetahui, baik perlawanan dinamik tanah maupun pengambilan contoh terganggu dengan teknik penumbukan. (SNI 4153:2008).

CPT merupakan pengujian tanah yang dilakukan di lapangan untuk mendapatkan nilai konus pada bagian ujung penetrasi dan nilai jumlah hambatan pelekat (SNI 2827-2008). Nilai konus yang didapat dari CPT dapat langsung digunakan untuk mendapatkan daya dukung tanah (Hardiyatmo, 1992).

Beberapa keunggulan CPT dibanding SPT yaitu lebih ekonomis, lebih cepat, dapat diulang dengan hasil relatif sama, korelasi terhadap daya dukung cukup sesuai, dan perkembangan yang meningkat dengan penambahan sensor pada CPT elektrik. Sedangkan kekurangan uji sondir yaitu tidak didapat contoh tanah, kedalaman penetrasi terbatas, serta tidak dapat menembus kerikil (Rahardjo, 2008). Sehingga CPT lebih sering digunakan pada proyek yang tidak berdiri pada tanah yang dominan kerikil dan tidak memerlukan contoh tanah pada setiap kedalaman penetrasinya. Namun terkait hasil data untuk yang digunakan untuk menentukan daya dukung pondasi dalam berdasarkan CPT, masih belum tahu kesesuainya dengan daya dukung berdasarkan data SPT, dimana data SPT dinilai lebih banyak korelasi dengan parameter lain.

Walaupun tidak ada contoh tanah pada pelaksanaan CPT, nilai sudut geser tanah dapat diperkirakan dengan menggunakan grafik yang diberikan oleh grafik hubungan nilai konus dengan jenis tanah (Robertson, 1990).

Biaya penyelidikan tanah hanya berkisar antara 0,5 sampai 1 persen dari keseluruhan biaya bangunan.
(Bowles, 1984). Sehingga untuk bangunan kecil yang nilai proyeknya tidak terlalu besar diperlukan jenis pengujian yang lebih ekonomis tetapi tetap dapat diterima hasil pengujiannya. Oleh karena itu untuk bangunan menengah ke bawah CPT lebih banyak digunakan dibandingkan SPT. Namun untuk hasil pengujiannya perlu dikaji lebih lanjut.

Oleh karena itu perlu adanya suatu perbandingan antara hasil perhitungan daya dukung berdasarkan data CPT dan data SPT. Dimana perbandingan tersebut diterapkan pada rencana proyek Pembangunan Gedung Parkir RSUD Dr. Soedono Madiun.

Proyek Pembangunan Gedung Parkir RSUD Dr. Soedono Madiun merupakan bangunan beton bertulang yang terdiri dari lima lantai yang akan difungsikan sebagai tempat parkir kendaraan karyawan dan keluarga pasien serta pengunjung rumah sakit. Gedung Parkir RSUD Dr. Soedono Madiun ini harus dapat memberikaan Jaminan Kehandalan Struktur, baik struktur atas maupun struktur bawah.

Sistem struktur bagian bawah bangunan ini dirancang menggunakan pondasi tiang yang disatukan dengan pilecap atau poer sesuai dengan beban dan daya dukung tanahnya.

\section{METODE PENELITIAN}

\section{Pengumpulan Data}

Proses pengumpulan data di dalam penelitian ini di mulai dengan pengamatan data dari pengujian tanah pada Proyek Pembangunan Gedung Parkir RSUD Dr. Soedono Madiun yang terdiri dari SPT dan CPT.

\section{Hubungan NSPT dengan Karakteristik Tanah}

Jumlah pukulan $(\mathrm{N})$ yang dari pengujan standar penetrasi (SPT) dapat dihubungkan dengan karakteristik suatu tanah seperti yang ditunjukan pada Tabel 1 dan Tabel 2, (Bowles J.E, 1984).

Tabel 1. Hubungan N-SPT dengan karakteristik tanah kohesi

\begin{tabular}{cc}
\hline N-SPT & Karakteristik tanah kohesi \\
\hline $0-4$ & very soft \\
\hline $4-6$ & soft \\
\hline $6-16$ & medium \\
\hline $16-25$ & stiff \\
\hline$>25$ & hard \\
\hline
\end{tabular}

Tabel 2. Hubungan N-SPT dengan karakteristik tanah non-kohesi

N-SPT Karakteristik tanah non-kohesi
$0-3$ very loose

Proteksi/Juni 2021 Volume 3 No. 1 


\begin{tabular}{cc}
\hline $4-10$ & Loose \\
\hline $11-30$ & medium \\
\hline $31-50$ & dense \\
\hline$>50$ & Very dense
\end{tabular}

Hubungan Konus dan Rasio Gesek dengan Karakteristik Tanah

Nilai konus dan rassio gesek yang didapat dari pengujian sondir (CPT) dapat dihubungkan dengan karakteristik suatu tanah seperti yang ditunjukan pada Gambar 1, (Robertson, 1983).

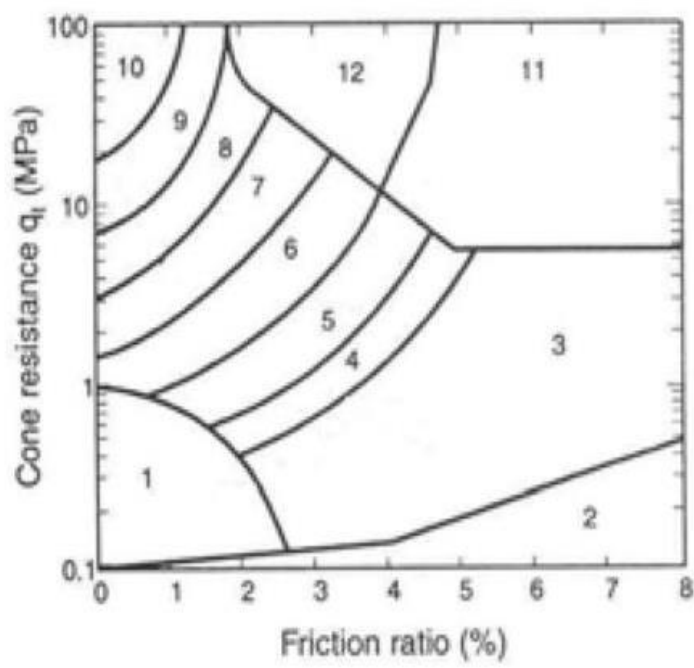

Gambar 1. Hubungan nilai konus dan rasio gesek dengan karakteristik tanah

keterangan:

$1=$ tanah sensitif

2 = tanah organik

3 = lempung

4 = lempung kelanauan s/d lempung

5 = lanau kelempungan s/d lempung kelanauan

6 = lanau kepasiran s/d lanau kelempungan

7 = pasir kelanauan s/d lanau kepasiran

8 = pasir $\mathrm{s} / \mathrm{d}$ pasir kelanauan

$9=$ pasir

$10=$ pasir berkerikil

$11=$ tanah berbutir halus sangat kaku

$12=$ pasir $\mathrm{s} / \mathrm{d}$ pasir berlempung sangat kaku

\section{Pengolahan Data}

Pengolahan data dilakukan dengan mencari titik CPT dan SPT yang berdekatan lokasi pengujiannya, kemudian dari data CPT dicari nilai konus, JHP (Jumlah hambatan pelekat), dan rasio gesek untuk memperkirakan jenis tanah berdasarkan data CPT sampai dengan kedalaman yang dikehendaki

Sedangkan dari data SPT dicari nilai N (jumlah pukulan) dan juga dicari elevasi muka air tanah pada data tersebut. kemudian dari nilai $\mathrm{N}$ tersebut dihitung nilai N koreksi dengan Persamaan [1] seperti yang dijelaskan oleh Terzaghi dan Peck (Wahyudi, 1999).

$N^{\prime}=15+0,5 \cdot(N-5)$

\section{Analisis Daya Dukung Berdasarkan Data SPT}

Luciano de court telah memberikan suatu penyelesaian untuk mendapatkan daya dukung limit pondasi tiang pancang berdasarkan data SPT pada berbagai karakteristik tanah seperti yang diberikan pada Persamaan [2], Persamaan [3], dan Persamaan [4], (Wahyudi, 1999).

$Q u=Q p+Q s$

$Q p=(N p x K) \times A p$

$Q s=\left(\frac{N s}{3}+1\right) x A s$.

dimana:

$\mathrm{Q}_{\mathrm{u}}=$ daya dukung limit tiang pancang (ton)

$\mathrm{Q}_{\mathrm{p}}=$ daya dukung ujung tiang (ton)

$\mathrm{K}=$ koefisien karakteristik tanah

$\mathrm{Q}_{\mathrm{s}}$ = daya dukung selimut tiang (ton)

$\mathrm{A}_{\mathrm{p}}=$ luas penampang dasar tiang $\left(\mathrm{m}^{2}\right)$

$\mathrm{A}_{\mathrm{s}}=$ luas selimut tiang (keliling $\mathrm{x}$ panjang tiang yang terbenam) $\left(\mathrm{m}^{2}\right)$

$\mathrm{N}_{\mathrm{p}}=$ harga rata-rata SPT sekitar 4B diatas hingga 4B dibawah dasar tiang pondasi

$\mathrm{N}_{\mathrm{s}}$ =harga rata-rata sepanjang tiang yang tertanam dengan batasan $3<50 \mathrm{~B}=$ diameter pondasi

Nilai koefisien karakteristik tanah tergantung dari jenis tanah di bagian ujung pondasi tiang pancang. Adapun nilai tersebut dapat dilihat pada Tabel 3.

Tabel 3. Koefisien karakteristik tanah

\begin{tabular}{lc} 
Karakteristik tanah & $\mathrm{K}\left(\mathrm{t} / \mathrm{m}^{2}\right)$ \\
\hline Lempung & 12 \\
\hline Lanau berlempung & 20 \\
\hline Lanau berpasir & 25 \\
\hline Pasir & 40
\end{tabular}

Analisis Daya Dukung Berdasarkan Data CPT

Begemann telah memberikan penyelesaian untuk mendapatkan daya dukung limit pondasi tiang pancang berdasarkan data CPT (sondir) seperti yang diberikan pada Persamaan [5], (Bowless, 1988).

Qall $=\left(\frac{q c . A}{3}\right)+\left(\frac{J H P . O}{5}\right)$

dimana :

$\mathrm{Q}_{\text {all }}=$ kapasitas beban yang diijinkan 
$\mathrm{qc}=$ nilai konus rata-rata sepanjang $8 \mathrm{D}$ bagian atas ujung tiang dan sepanjang 3,5D bagian bawah ujung tiang

A =luas penampang dasar pondasi tiang

JHP = jumlah hambatan pelekat

$\mathrm{O}=$ keliling pondasi tian

\section{Kapasitas Daya Dukung Kelompok Tiang}

Jarak antar tiang pancang pada susunan pondasi kelompok tiang yaitu sekitar 2,5D -3,5D. Kapasitas limit kelompok tiang dihitung dengan mempertimbagkan faktor efisiensi yang dinyatakan dengan Persamaan [6] dan Persamaan [7], (Das, 2011).

$Q_{g(u)}=E \cdot \Sigma Q_{u}$

$E=1-\frac{D}{\pi \cdot d \cdot n 1 \cdot n 2}[n 1(n 2-n 1)+n 2(n 1-1)$

$+2(n 1-1)(n 2-n 1)$

dimana:

$Q_{g(u)}=$ daya dukung limit kelompok tiang pancang

$Q_{u}=$ daya dukung limit tiang pancang tunggal

$\mathrm{E}=$ efesiensi kelompok tiang

$\mathrm{n}_{1} \quad=$ jumlah tiang pancang arah memanjang

$\mathrm{n}_{2} \quad=$ jumlah tiang pancang arah melintang

$\mathrm{D}=$ dimensi/ diameter tiang pancang

d = jarak antara tiang pancang

$\Sigma \quad=$ jumlah tiang pancang

\section{Diameter tiang pancang}

Diiameter tiang pancang yang digunakan pada penelitian ini mengacu pada kondisi lapangan pada Proyek Pembangunan Gedung Parkir RSUD Dr. Soedono Madiun, sehingga alternatif dimensi tiang pancang yang dipilih akan dapat mudah dilaksanakan di lapangan. Adapun variasi alternatif diameter tiang pancang pada penelitian ini dapat yaitu $\varnothing 50 \mathrm{~cm}, \varnothing 40 \mathrm{~cm}, \varnothing 30 \mathrm{~cm}$.

\section{Beban pondasi}

Beban pondasi ditentukan berdasarkan pemodelan struktur Gedung Parkir RSUD Dr. Soedono Madiun yang dilakukan menggunakan SAP 2000. Dari analisis tersebut maka didapat reaksi dasar pada setiap titik tumpu dasar bangunan antara lain:gaya veritkal, momen arah melintang dan momen arah memanjang. Pada penelitian ini beban yang dianalisa adalah beban yang paling besar.

\section{Alur penelitian}

Analisis daya dukung tiang pancang dengan berbagai dimensi/diameter penampang dilakukan untuk dapat melihat masing daya dukung dari penampang tersebut. Kemudian dilakukan kontrol terhadap beban yang bekerja pada pondasi tersebut. Pada setiap analisis dapat dibandingkan antara hasil analasis daya dukung yang berdasarkan data SPT dengan hasil analasis daya dukung yang berdasarkan data CPT. Gambar diagram alir penelitian ini dapat dilihat pada Gambar 2.

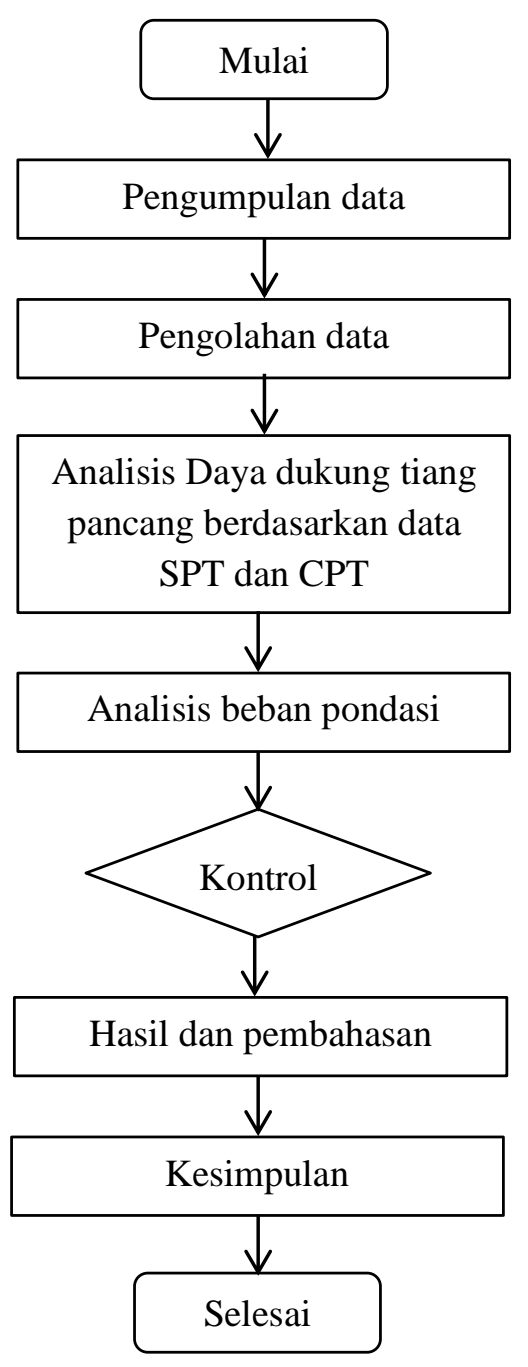

Gambar 2. Diagram Alir penelitian

\section{HASIL DAN PEMBAHASAN}

\section{Nilai N Koreksi Berdasarkan Data SPT}

Dari data pengujian standar penetrasi (SPT) pada Proyek Pembangunan Gedung Parkir RSUD Dr. Soedono Madiun di titik BH-1, didapat diskripsi jenis tanah dan jumlah pukulan $(\mathrm{N})$ di setiap kedalaman (z), dengan interval $2 \mathrm{~m}$ seperti yang ditunjukan pada Tabel 4. Muka air tanah berada 
sekitar $6 \mathrm{~m}$ dari perrmukaan tanah. Dengan data tersebut maka dapat dihitung nilai $\mathrm{N}_{\text {koreksi. }}$.

\section{Data CPT}

Dari data pengujian sondir (CPT) pada Proyek Pembangunan Gedung Parkir RSUD Dr. Soedono Madiun di titik S1, didapat nilai konus (qc) dan rasio gesek (Fr) pada setiap kedalaman. Dengan data tersebut maka dapat diperkirakan karekteristik tanah di setiap kedalaman seperti yang ditunjukan pada Tabel 5. Hasil estimasi atau perkiraan jenis tanah berdasarkan data CPT menyerupai pengamatan visual dari data SPT.

Tabel 4. NSPT, Jenis tanah, dan perhitungan $\mathrm{N}_{\text {koreksi }}$

\begin{tabular}{cccc}
\hline $\begin{array}{c}\mathrm{Z} \\
(\mathrm{m})\end{array}$ & $\begin{array}{c}\mathrm{N} \\
(\mathrm{blw})\end{array}$ & $\begin{array}{c}\text { Diskripsi jenis } \\
\text { tanah }\end{array}$ & $\mathrm{N}_{\text {korelsi }}$ \\
\hline 2 & 5 & Lanau kelempungan & 10,0 \\
\hline 4 & 12 & $\begin{array}{c}\text { Lanau kelempungan } \\
\text { Lanau kelempungan } \\
\text { sedikit batu kerikil }\end{array}$ & 13,5 \\
\hline 6 & 13 & $\begin{array}{c}\text { Lanau kelempungan } \\
\text { berpasir halus }\end{array}$ \\
\hline 8 & 25 & 20,0 \\
\hline 10 & 28 & $\begin{array}{c}\text { Lanau kelempungan } \\
\text { berpasir halus }\end{array}$ \\
\hline 12 & 35 & $\begin{array}{c}\text { Lanau kelempungan } \\
\text { berpasir halus }\end{array}$ & 21,5 \\
\hline 14 & 39 & Lanau berpasir \\
\hline 16 & 43 & Lanau kelempungan \\
\hline 18 & 56 & $\begin{array}{c}\text { Lanau kelempungan } \\
\text { berpasir }\end{array}$ & 26,0 \\
\hline 20 & 59 & $\begin{array}{c}\text { Lanau kelempungan } \\
\text { berpasir }\end{array}$ & 29,0 \\
\hline & \multicolumn{3}{c}{35,5} \\
\hline
\end{tabular}

Tabel 5. Konus, rasio gesek, dan estimasi jenis tanah

\begin{tabular}{cccc}
\hline $\mathrm{z}$ & $\mathrm{qc}$ & $\mathrm{Fr}$ & Diskripsi jenis tanah \\
$(\mathrm{m})$ & $(\mathrm{MPa})$ & $(\%)$ & \\
\hline 2 & 0,6 & 5 & Lempung \\
\hline 4 & 2,4 & 2 & Lanau kelempungan \\
\hline 6 & 5,0 & 3 & Lanau kelempungan \\
\hline 8 & 7,0 & 3 & Lanau kelempungan \\
\hline 10 & 10 & 2 & Lanau berpasir \\
\hline 12 & 6 & 3 & Lanau kelempungan \\
\hline 13 & 16 & 1 & Pasir kelanauan \\
\hline
\end{tabular}

\section{Kedalaman Tiang Pancang}

Secara keseluruhan hasil CPT dan SPT memiliki kesamaan tentang diskripsi tanah yaitu secara gasir besar adalah lanau. Pada Tabel 4 menunjukan bahwa pada kedalaman 12 - 14 merupakan lanau kelempungan berpasir dengan nilai $\mathrm{N}$ sebesar $35-39$ sehingga dapat dikategorikan sebagai tanah padat. Sedangkan Tabel 5 juga menunjukan nilai konus pada kedalaman $13 \mathrm{~m}$ sebesar $16 \mathrm{MPa}>15 \mathrm{MPa}$, sehingga juga dapat dikategorikan sebagai tanah padat. Oleh karena itu kedalaman tiang pancang dalam penelitian ini ditentukan pada kedalaman $13 \mathrm{~m}$.

\section{Beban Pondasi}

Gaya vertikal maksimal yang didapat dari SAP 2000 Gedung Parkir RSUD Dr. Soedono Madiun pada pondasi / tumpuan nomor 11 yang berada di tengah - tengah bangunan yaitu sebesar $6058 \mathrm{kN}$, dengan momen arah melintang sebesar $1,71 \mathrm{kNm}$ dan momen arah melintang sebesar $0,31 \mathrm{kNm}$.

\section{Daya Dukung Berdasarkan Data SPT}

Hasil perhitungan daya dukung tiang pancang tunggal berdasarkan data SPT dengan faktor keamanan 2 dapat dilihat pada Tabel 6 .

Tabel 6. Daya dukung tiang pancang berdasarkan data CPT pada kedalaman $13 \mathrm{~m}$

\begin{tabular}{cccc}
\hline $\begin{array}{c}\text { Diameter } \\
(\mathrm{cm})\end{array}$ & $\begin{array}{c}\text { Luas } \\
\left(\mathrm{cm}^{2}\right)\end{array}$ & $\begin{array}{c}\text { Keliling } \\
(\mathrm{cm})\end{array}$ & $\begin{array}{c}\text { Daya } \\
\text { dukung } \\
(\text { ton })\end{array}$ \\
\hline 30 & 706,85 & 94,25 & 83,6 \\
\hline 40 & 1256,64 & 125,66 & 119,6 \\
\hline 50 & 1963,50 & 157,08 & 159,7 \\
\hline
\end{tabular}

\section{Daya Dukung Berdasarkan Data CPT}

Hasil perhitungan daya dukung tiang pancang tunggal berdasarkan data CPT di kedalaman $13 \mathrm{~m}$ dengan $\mathrm{JHP}=1740 \mathrm{~kg} / \mathrm{cm}$ dapat dilihat pada Tabel 7.

Tabel 7. Daya dukung tiang pancang berdasarkan data CPT pada kedalaman $13 \mathrm{~m}$

\begin{tabular}{cccc}
\hline $\begin{array}{c}\text { Diameter } \\
(\mathrm{cm})\end{array}$ & $\begin{array}{c}\text { Luas } \\
\left(\mathrm{cm}^{2}\right)\end{array}$ & $\begin{array}{c}\text { Keliling } \\
(\mathrm{cm})\end{array}$ & $\begin{array}{c}\text { Daya } \\
\text { dukung } \\
\text { (ton) }\end{array}$ \\
\hline 30 & 706,85 & 94,25 & 70,50 \\
\hline 40 & 1256,64 & 125,66 & 110,75 \\
\hline 50 & 1963,50 & 157,08 & 159,38 \\
\hline
\end{tabular}

\section{Efesiensi Kelompok Tiang}

Hasil perhitungan efesiensi daya dukung kelompok tiang pancang dengan jarak antar tiang sebesar 3D dapat dilihat pada Tabel 8.

Tabel 8. Efeiensi daya dukung kelompok tiang

\begin{tabular}{cc}
\hline Tiang & Efesiensi \\
\hline 2 & 0,95 \\
\hline 4 & 0,86 \\
\hline 6 & 0,83 \\
\hline 8 & 0,82 \\
\hline 9 & 0,80 \\
\hline 12 & 0,78 \\
\hline
\end{tabular}

\section{Daya Dukung Kelompok Tiang Berdasarkan Data SPT}

Jumlah tiang pancang yang diperlukan untuk menahan beban maksimum di titik tumpu nomor 11 
menurut daya dukung berdasarkan data SPT dapat dilihat pada Tabel 9.

Tabel 9. Jumlah tiang pancang berdasarkan data SPT pada kedalaman $13 \mathrm{~m}$

\begin{tabular}{ccc}
\hline $\begin{array}{c}\text { Diamete } \\
\mathrm{r} \\
(\mathrm{cm})\end{array}$ & $\begin{array}{c}\Sigma \text { Tiang } \\
(\mathrm{bh})\end{array}$ & $\begin{array}{c}\text { Kapasitas kelompok tiang } \\
\text { (ton) }\end{array}$ \\
\hline 30 & 12 & 712 \\
\hline 40 & 8 & 785 \\
\hline 50 & 6 & 795 \\
\hline
\end{tabular}

\section{Daya Dukung Kelompok Tiang Berdasarkan Data CPT}

Jumlah tiang pancang yang diperlukan untuk menahan beban maksimum di titik tumpu nomor 11 menurut daya dukung berdasarkan data SPT dapat dilihat pada Tabel 10.

Tabel 10.Jumlah tiang pancang berdasarkan data CPT pada kedalaman $13 \mathrm{~m}$

\begin{tabular}{ccc}
\hline $\begin{array}{c}\text { Diamete } \\
\text { r } \\
(\mathrm{cm})\end{array}$ & $\begin{array}{c}\Sigma \text { Tiang } \\
\text { (bh) }\end{array}$ & $\begin{array}{c}\text { Kapasitas kelompok tiang } \\
\text { (ton) }\end{array}$ \\
\hline 30 & 12 & 660 \\
\hline 40 & 8 & 727 \\
\hline 50 & 6 & 782 \\
\hline
\end{tabular}

\section{KESIMPULAN}

Berdasarkan hasil analisis dan pembahasan mengenai data SPT, CPT, daya dukung tiang pancang tunggal, dan kapasitas kelompok tiang dalam menahan beban makasimum dari bangunan seperti yang telah diuraiakn sebelumnya, maka didapat beberapa kesimpulan sebagai berikut:

1. Hasil estimasi perkiraan jenis tanah dari data CPT secara garis besar sama dengan diskripsi visual jenis tanah dari data SPT. Dimana secara garis besar jenis tanah di dominasi oleh lanau.

2. Hasil SPT pada titik BH-1 dan CPT pada titik S1 kedalaman $13 \mathrm{~m}$, keduanya memberikan informasi kriteria yang sama yaitu pada kedalaman tersebut merupakan tanah padat.
3. Hasil perhitungan daya dukung tiang pancang tunggal berdasarkan data SPT dan CPT pada kedalaman $13 \mathrm{~m}$, untuk diameter $30 \mathrm{~cm}, 40 \mathrm{~cm}$, $50 \mathrm{~cm}$, masing - masing hasil perhitungan tersebut memberikan hasil yang relatif sesuai satu sama lain.

4. Hasil perhitungan kapasitas daya dukung kelompok tiang pancang berdasarkan data SPT dan CPT pada kedalaman $13 \mathrm{~m}$, untuk diameter $30 \mathrm{~cm}, 40 \mathrm{~cm}, 50 \mathrm{~cm}$, masing - masing hasil perhitungan tersebut memberikan jumlah tiang pancang yang relatif sesuai satu dengan yang lainnya dalam menahan beban maksimum bangunan tersebut.

\section{REFERENSI}

Bowles, Joseph E. 1984. Sifat-sifat Fisis dan Geoteknis Tanah. Jakarta: Erlangga.

Bowless, J.E. 1988, Analisis dan Desain Pondasi Edisi Keempat Jilid 2, Erlangga.

Das, Braja M. 1986. Soil Mechanics Laboratory Manual. California: Engineering Press,Inc

H. Wahyudi. 1999. Daya Dukung Pondasi Dalam. Surabaya: Jurusan Teknik Sipil FTSP ITS

Hary Christady Hardiyatmo. 1992. Mekanika Tanah, Gramedia Pustaka Utama. Jakarta.

L. DeCourt and A. Quaresma. 1978. Capacidade de carga de estacas a partir de valores de SPT. Congr. Bras. MECÂNICA DOS SOLOS E Eng. FUNDAÇÕES, vol. 1, no. 6, pp. 45-53

LH, Shiley. 1994.Geoteknik dan Mekanika Tanah (penyelidikan Lapangan \& Laboratorium. Bandung: Nova.

Robertson, P.K. 1990. Soil classification using the cone penetration test. Canadian Geotechnical Journal, 27(1): 151-158.

Rahardjo, P. P. 2008. Penyelidikan Geoteknik dengan Uji Insitu. GEC UK-Parahyangan, Bandung.

SNI 4153. 2008. Cara uji penetrasi lapangan dengan SPT. Jakarta. Badan Standardisasi Nasional

SNI 2827. 2008. Cara uji penetrasi lapangan dengan alat sondir. Jakarta. Badan Standardisasi Nasional 